\title{
Evaluation of the effect of Superpave aggregate gradations on Marshall mix design parameters of wearing course
}

\author{
W.K. Mampearachchi ${ }^{1 *}$ and P.R.D. Fernando ${ }^{2}$ \\ ${ }^{I}$ Department of Civil Engineering, Faculty of Engineering, University of Moratuwa, Moratuwa. \\ ${ }^{2}$ Planning Division, Road Development Authority, Sethsiripaya, Battaramulla.
}

\begin{abstract}
The purpose of this study was to evaluate the effect of the Superpave specified aggregate gradation on Marshall mix design parameters. Twenty eight (28) asphalt concrete mixtures were prepared in three types of gradations such that the gradations were above, through and below the Superpave restricted zone. Samples were prepared for Marshal mix design and tested in the laboratory to evaluate the Marshall stability, flow and volumetric properties.
\end{abstract}

Statistical analysis showed that all three types of mixtures, above, through and below the restricted zone, did not have any significant difference on Marshall stability and void in mineral aggregate (VMA). The mixtures with gradation passing below the restricted zone showed higher air voids $\left(\mathrm{V}_{\mathrm{a}}\right)$ and lower flow values than gradation passing above and through the restricted zone. The results indicated that Superpave specified aggregate gradation could be used as a guide to select aggregate gradations for wearing courses. Aggregate gradation below the restricted zone requires $0.5 \%$ less bitumen than typical mix designs and has a lower binder tolerance limit.

Keywords: Aggregate gradation, Marshall parameters, restricted zone, Superpave gradation, wearing course.

\section{INTRODUCTION}

Many empirical and semi empirical design procedures for hot mix asphalt (HMA) design have been devised, which first attempted to evaluate various properties of bituminous mixtures. Some of the more widely known of these design procedures are the Marshall, Hveem, Superpave, Texas and University of Nottingham methods (O’Flaherty et al., 2002).

\section{Marshall method}

Bruce Marshall developed the first version of the Marshall mix design method in 1939. The Marshall method uses a drop hammer to compact samples, and the stability and flow are tested in a confined compression mould. The volumetric characteristics of the mix are also evaluated. In 1943, the Corps of Engineers Waterways Experiment Station began experimenting with the Marshall testing apparatus and developed a series of laboratory and field experiments. A variety of compaction efforts were used to produce lab densities that were similar to field densities under construction and aircraft loads. Laboratory methods consisted of different weights of drop hammer, combinations of numbers of blows per side, compactor foot designs and mould bases (Roberts et al., 1996).

The Marshall procedures have been standardized by the American Society for Testing and Material (ASTM) and published as ASTM D 1559. The method is applicable only to hot mixtures using penetration grade asphalt cement and containing aggregates with a maximum size of $25 \mathrm{~mm}$ ( $1 \mathrm{in}$.) or less [a modified method has been proposed to allow testing of paving mixtures containing aggregates with maximum size up to $38 \mathrm{~mm}(1.5 \mathrm{in})$.$] . The Marshall method uses standard$ test specimens; $64 \mathrm{~mm}$ (2.5 in.) in height and $102 \mathrm{~mm}$ (4 in.) in diameter. They are prepared using a standard procedure for heating, mixing and compaction of the asphalt - aggregate mixtures (Wright, 1996).

\section{Superpave method}

In 1987, the Strategic Highway Research Programme (SHRP), USA began developing a new system for specifying asphalt material. The final output of the SHRP asphalt research programme was a new system called

* Corresponding author (wasanthak@civil.mrt.ac.lk) 
Superior Performing Asphalt Pavement (SUPERPAVE). Superpave represents an improved system for specifiying asphalt binder and mineral aggregates, developing asphalt mixture design and analyzing and establishing pavement performance prediction.

A Superpave mix design involves selecting asphalt and aggregate materials that meet the Superpave specifications and then conducting volumetric analysis. Hot mix asphalt specimens were compacted with the Superpave gyratory compactor. Two new key factors in the Superpave system are laboratory compaction and performance testing. Laboratory compaction is accomplished using a Superpave gyratory compactor (SGC), while the main purpose of SGC is to compact test specimens. The SGC can also provide information about the compactability of the particular mixture by capturing data during compaction.

The performance based tests and performance prediction models for HMA are important developments from the SHRP asphalt research. Output from these tests is used to make detailed predictions of actual pavement performance. Test procedure and performance prediction models were developed, that allows an engineer to estimate the performance life of a prospective HMA in terms of equivalent single axle loads (ESAL).

The SHRP research effort was mainly concentrated on properties and testing of asphalt binder (Jahn, 1996). The aggregate and asphalt-aggregate characteristics of Superpave mixture were developed by the Aggregate Expert Task Group (ETG) of SHRP, and they used a modified Delphi procedure to select the aggregate and mixture characteristics (Anderson \& Bahia, 1997).
To specify the aggregate gradation, Superpave has adopted the 0.45 power curve with gradation control points and a restricted zone. Another important feature of the 0.45 power curve is that it represents the maximum density line. This line represents a gradation, where the aggregate particles fit together to make the densest arrangement. Furthermore, gradation above the maximum density line makes finer gradations, while gradation below the maximum density line makes coarser gradations. The control points function as upper and lower limits of the aggregate gradation, which should be satisfied by the selected aggregate. They are placed at three specific points; nominal maximum sieve, an intermediate sieve $(2.36 \mathrm{~mm})$, and the smallest sieve $(0.075 \mathrm{~mm})$.

The four upper control points are a result of the definition of nominal maximum and maximum size. The lower control point at $0.075 \mathrm{~mm}$ limits the minimum and maximum percentages of $0.075 \mathrm{~mm}$ size specified in ASTM D 3515 for dense graded asphalt mixtures. Gradation control points at the $2.36 \mathrm{~mm}$ sieve size control the amount of sand size particles in the mixture. The upper control point limits the amount of sand in the mixture to avoid sand - asphalt mixtures and the lower control point ensures that adequate sand is contained to make a dense graded mixture.

The restricted zone resides along the maximum density gradation line between the $2.36 \mathrm{~mm}$ sieve and the $0.3 \mathrm{~mm}$ sieve. The restricted zone encourages development of gap graded mixtures (mixtures, which pass below the restricted zone are gap graded). Figure 1 and Table 1 show the control points, restricted zone and gradation limits for a $19.0 \mathrm{~mm}$ Superpave mixture, respectively.

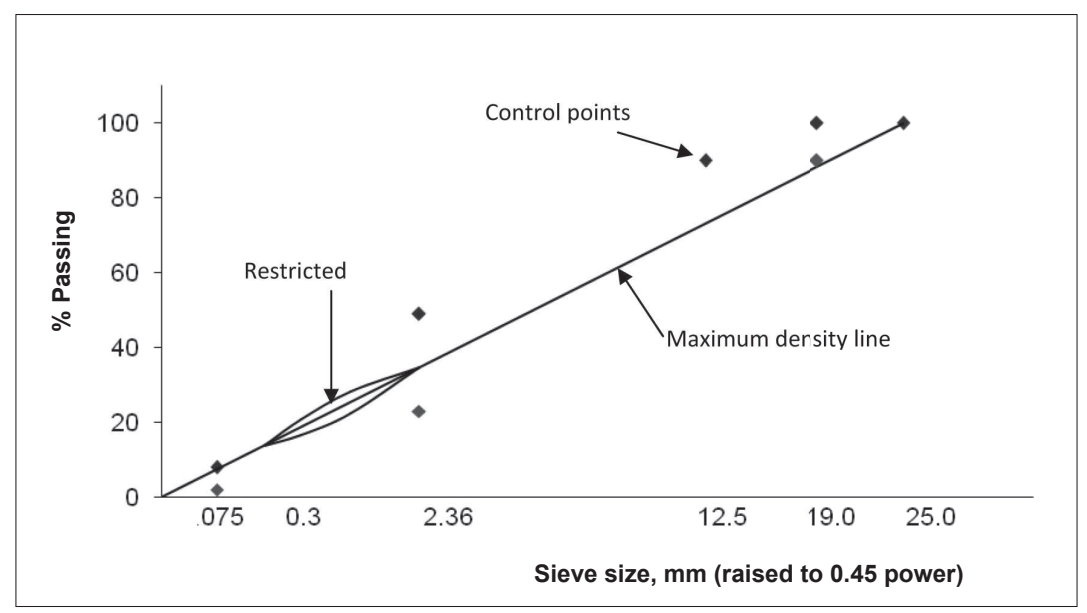

Figure 1: Superpave specified gradation for $19.0 \mathrm{~mm}$ nominal size 
Superpave specified aggregate gradation for HMA (AC type) wearing course are presented in Table 1 (Asphalt Institute, 1996).

\section{Aggregate gradation specifications for wearing course}

Separate grading requirements are usually given for the separate aggregate components of the mixture: coarser aggregate, fine aggregate and filler, and overall specifications are given pertaining to the composition

Table 1: Superpave asphalt mixture gradation requirements

\begin{tabular}{|c|c|c|c|c|}
\hline \multirow[t]{3}{*}{ Sieve, $\mathrm{mm}$} & \multicolumn{4}{|c|}{$19 \mathrm{~mm}$ nominal size } \\
\hline & \multicolumn{2}{|c|}{ Control points } & \multicolumn{2}{|c|}{ Restricted zone boundary } \\
\hline & Minimum & Maximum & Minimum & Maximum \\
\hline 25.0 & & 100.0 & & \\
\hline 19.0 & 90.0 & 100.0 & & \\
\hline 12.5 & & 90.0 & & \\
\hline \multicolumn{5}{|l|}{9.5} \\
\hline \multicolumn{5}{|l|}{4.75} \\
\hline 2.36 & 23.0 & 49.0 & 34.6 & 34.6 \\
\hline 1.18 & & & 22.3 & 28.3 \\
\hline 0.600 & & & 16.7 & 20.7 \\
\hline 0.300 & & & 13.7 & 13.7 \\
\hline \multicolumn{5}{|l|}{0.150} \\
\hline 0.075 & 2.0 & 8.0 & & \\
\hline
\end{tabular}

Source: Asphalt Institute SP-2 (1996)

Table 2: Gradation standards of wearing course

\begin{tabular}{|c|c|c|c|c|c|c|}
\hline \multirow{3}{*}{$\begin{array}{l}\text { Sieve } \\
\text { size }\end{array}$} & \multicolumn{6}{|c|}{$\%$ Passing } \\
\hline & \multicolumn{2}{|c|}{ ASTM } & \multicolumn{2}{|c|}{ SSCM } & \multicolumn{2}{|c|}{ CSRS } \\
\hline & Min. & Max. & Min. & Max. & Min. & Max. \\
\hline 25 & 100 & & 100 & 100 & & \\
\hline 19 & 90 & 100 & 90 & 100 & 100 & 100 \\
\hline 13.2 & & & & & 84 & 100 \\
\hline 12.5 & & & & & & \\
\hline 9.5 & 56 & 80 & 65 & 93 & 70 & 92 \\
\hline 4.75 & 35 & 65 & 45 & 73 & 50 & 70 \\
\hline 2.36 & 23 & 49 & 35 & 58 & 37 & 55 \\
\hline 1.18 & & & 26 & 48 & 26 & 41 \\
\hline 0.6 & & & 18 & 38 & 16 & 28 \\
\hline 0.3 & 5 & 19 & 13 & 26 & 12 & 20 \\
\hline 0.15 & & & 8 & 20 & 8 & 15 \\
\hline 0.075 & 2 & 8 & 4 & 12 & 4 & 10 \\
\hline
\end{tabular}

Source: American Society of Testing Materials (ASTM) D3515 (2001b), SSCM (1989), Committee of State Road Authorities (CSRA) 1987 of the paving mixture itself. The different specifications have been introduced by different agencies. Specifications of ASTM 3515, standard specification for construction and maintenance of roads and bridges (called SSCM in Sri Lanka) and the committee of state road authorities (CSRA) are a few of them and shown in Table 2.

\section{Aggregate gradation}

Elliot et al. (1991) carried out an investigation to evaluate the relationship between different aggregate gradations and properties of asphalt mixtures. The different aggregate blends were made as coarse, fine, mid-band (job mix formula - JMF), and two poorly graded materials; from coarser than JMF to finer than JMF (coarse-fine), and from finer than JMF to coarser than JMF (fine-coarse). From this investigation, Elliot et al. (1991) concluded that:

- When the shape of the gradation curve is changed (coarse to fine and fine to coarse gradation), variations in gradation have the greatest effect on mixture properties.

- Fine gradation enhances the Marshall stability, while the fine - coarse poor gradation reduces the Marshall stability. However, all of the gradations were found to have stability values that are considered to be more than adequate.

- Fine - coarse gradation increases the Marshall air voids and VMA, while the coarse - fine gradation reduces the Marshall air voids and VMA.

- Coarse-fine gradation produces the highest Marshall flow while fine-coarse gradation produces the lowest.

When the mixture gradation approaches the Fuller curve (maximum density line), it minimizes VMA and produces a mixture that will be very sensitive to proportioning errors. The best practice is to keep the blend away from the maximum density line (TRL, 2002).

In order to avoid any permanent deformation of HMA pavements, the following recommendations were made by Kennedy et al. (1996 cited in Chowdhury et al., 2001).

- Avoid gradation near the maximum density line, because it produces a well pack mixture, thus such mixtures have relatively low voids. Low void mixtures are very sensitive to asphalt binder content and the risk of flushing.

- Use angular aggregate particles because they provide greater interlock and internal friction, thus, such mixtures exhibit greater mechanical stability when compared to rounded particles. 
- Use aggregate with rough surface texture to create higher VMA in compacted mixtures and a good mechanical bond

A chosen blend of aggregate particles suitable for dense asphalt concrete surfacing shall have a sufficient VMA to be durable in service and retain a minimum of $3 \%$ air voids after secondary compaction by traffic (TRL, 2002).

\section{Fine aggregates}

Often, the content of fines in the mixture must be limited. Excessive amount of fines may result in a weak mixture, since the large particles would not be in contact with each other. The strength of the mixture would then depend only on the friction between the small particles, which is much less than between large particles (Atkins, 1997).

The amount of material passing the $4.75 \mathrm{~mm}$ sieve is one of the major factors contributing to the tenderness of an asphalt concrete mixture. In addition, rounded, uncrushed aggregates are more likely to make soft mixtures. The amount of uncrushed material passing $4.75 \mathrm{~mm}$ sieve increases the susceptibility of the mixture to adverse permanent deformation (Crawford, 1989).

The total deformation and the rate of permanent deformation is increased when the percentage of natural sand increases. Shape and texture of the fine aggregate plays a major role in controlling the plastic deformation in HMA. Natural particle content of an asphalt mixture in a high volume pavement should be limited to 10 to 15 percent, depending on other characteristics of the mixture (Button et al., 1990).

The angularity and the roughness of the crushed fine aggregate contribute to the increased strength of asphalt mixtures. Some amounts of crushed fine aggregate with natural aggregate in asphalt mixture is required to have stability for high quality pavements (Lottman \& Goetz, 1956).

Kallas and Griffith (1957) carried out research studies to estimate the influence of fine aggregates on asphalt paving mixtures. They pointed out that an increase in angularity of crushed fines increased the Marshall stability value at the optimum asphalt content, and also increased the void content at a given compaction level and the optimum asphalt content.

Replacing natural sand material with crushed fine aggregate increases the stability of Marshall specimens, reduces plastic deformation, reduces asphalt content sensitivity and increases VMA and air voids in the compacted specimen (Shklarsky \& Livneh, 1964).

\section{Coarse aggregate}

A study was conducted by Brown and Bassett (1990), to determine the relationship between asphalt mixture properties and maximum aggregate size. The above study showed that increasing the size of the largest aggregate in a gradation will increase the mixture quality with respect to creep performance, resilient modulus and tensile strength, while Marshall stability does not have a significant effect from the maximum size in gradation.

The coarser aggregates used for production of HMA should be made by crushing sound, un-weathered rock and natural gravel. Gravel should be crushed to produce at least two fractured faces on each particle (TRL, 2002). The aggregate should have the following characteristics:

- Be clean and free of clay and organic material

- Be angular and not excessively flaky to achieve good mechanical interlock

- Be strong enough to resist crushing during mixing, laying and service

- Be resistant to abrasion and polishing when exposed to traffic

- Be non-absorptive to make good mix design

- Have good affinity with bitumen

Kim et al. (1992) demonstrated that gradation had no effect on permanent deformation, while aggregate type has a significant effect on fatigue resistance and permanent deformation of asphalt concrete. Interaction of aggregate type with gradation, asphalt type, air voids, and temperature were critical factors for the permanent deformation of asphalt concrete.

Increases in the percentage of crushed coarse aggregate resulted in increased Marshall stability and resistance to permanent deformation. They also recovered a significant relationship between rutting potential and the shape of the coarse aggregate particles (Yeggoni et al., 1994).

\section{Filler}

Filler is mineral matter consisting of particles passing the $0.075 \mathrm{~mm}$ sieve. Mineral filler may consist of stone dust, fly-ash, hydrated lime, Portland cement, blast-furnace cement or any combination of these. In an asphalt mix, the filler acts as an extender to the binder and performs two important functions.

1. It acts as a voids filling material to enhance density and durability of the mixture.

2. It stiffens the mixture and improves resistance to plastic deformation. 
Increasing the stiffness of the mixture will depend on the type of filler, bulk density and the volumetric contribution in the mixture (CSRA, 1987).

Some materials can stiffen an asphalt binder, which would increase the Marshall stability. For example, a small increase in the mineral filler (dust) content of the asphalt mixture will stiffen the asphalt binder and the total asphalt mixture, leading to a high Marshall stability value. However, if too much mineral filler is used, the filler can act as an asphalt binder extender, affecting the mixture as if it had a higher asphalt binder content, leading to a decreased Marshall stability value (Roberts et al., 1996). Therefore, some agencies specify the maximum dust (passing the $75 \mu \mathrm{m}$ sieve) to asphalt binder content ratio as a guideline in mix design. Most specifications use a maximum value of 1 or 1.2 at the laboratory design stage. The maximum value of 1.0 or 1.2 usually applies only to dense graded asphalt mixtures.

From various laboratory and field studies, it is concluded that additional minus No. 200 material tends to produce lower optimum asphalt content, a higher stability, and a more asphalt sensitive mixture. Some filler is required for stability while an excessive amount (greater than $6 \%$ in conventional mixtures) will produce undesirable mixtures (Brown et al., 1989).

The mineral filler characteristics vary not only with the type, gradation, and amount of the filler but also with its particle size. If the size of mineral filler particles is smaller than the asphalt film thickness in the HMA, the filler acts as an extender of the asphalt binder. However, if an excessive amount of large size mineral filler is present, the asphalt demand may increase (Tarris \& Anderson, 1982).

\section{Restricted zone}

Research has been focused on the effect of restricted zone on the performance of HMA (Hand \& Epps, 2004). This indicated that good performance can be achieved with fine graded mixtures and, in most cases, fine Superpave mixtures out - perform coarser Superpave mixtures. This study has concluded that there is no correlation between the Superpave restricted zone and HMA permanent deformation or fatigue performance.

Superpave restricted zone does not affect the VMA and particle interlock, if the blend contains only crushed aggregates. Therefore, the restricted zone is not adopted as an essential requirement of local specifications, rather that it is an option for heavily trafficked roads (TRL, 2002)

Superpave coarse mixtures (gradation passing below the restricted zone) will normally provide the most effective material for roads on very heavily trafficked and severe sites (TRL, 2002).

Rouque et al. (1997) showed that a broad range of aggregate gradations ranging from restricted zone to stone matrix asphalt could yield good shear resistance in HMA. This study has also shown that gradation of the coarse aggregate fraction is the most critical factor affecting the shear resistance of the HMA and that VMA could not be related to shear resistance of the mixture.

Hand et al. (2001) have reported that both laboratory and prototype-scale performance tests indicated that adequate rutting performance could be achieved with gradations above, through, and below the restricted zone. They found that above and through restricted zone mixtures might show slightly better performance than below mixtures.

Another study (Jahn, 1996) has focused on 128 trial aggregate blends used for mixture design to setup a guideline for the mixture designers; more specially, the blends were examined to find the gradation or gradation characteristics, which can yield the required VMA for the asphalt concrete. He tried to find a correlation between VMA and the distance from maximum density line on the 0.45 power gradation chart or distance from the restricted zone and did not find any statistically significant relationship between VMA in the HMA and the sum of the distances from the Superpave maximum density line or the sum of the distance from the restricted zone. The same study, designed and evaluated HMA of four different gradations using only one aggregate source.

The combined gradations were as follows;

- $\mathrm{S}$ - shaped coarse gradation

- Fine gradation above the restricted zone

- Intermediate gradation passing through the restricted zone

- S shaped coarse but with slightly humped gradation

The asphalt mixtures were evaluated using the Superpave shear tester and the researchers noticed that the gradation above restricted zone performed the best, and those below restricted zone performed the worst. 


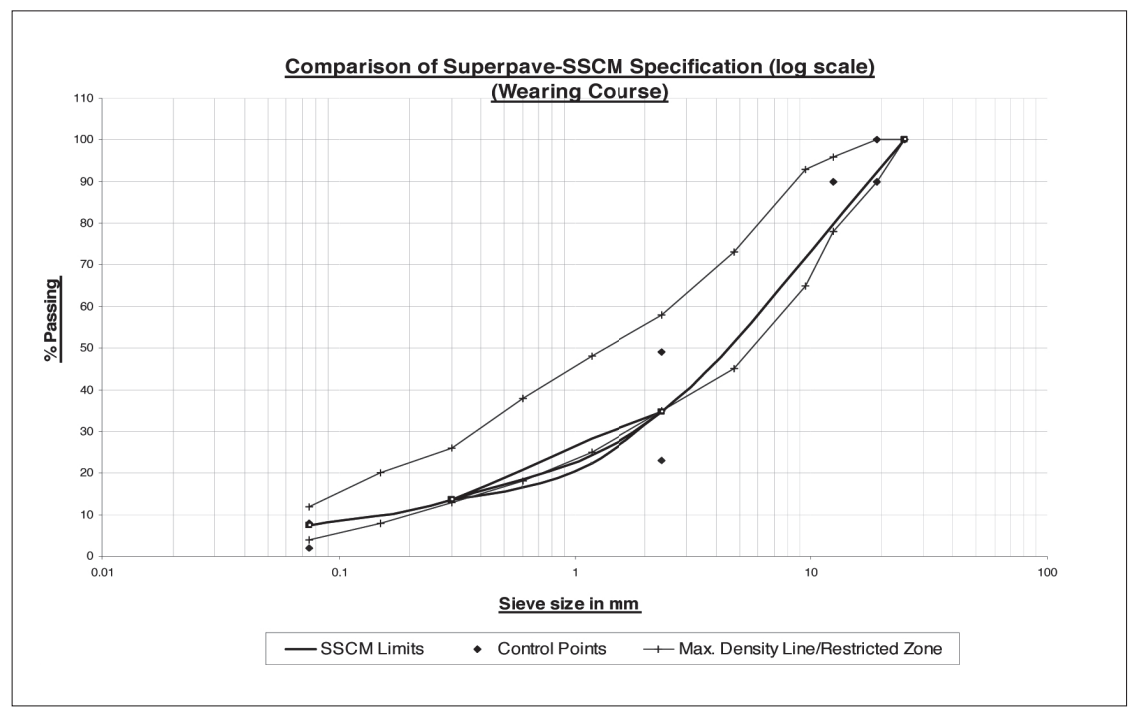

Figure 2: Superpave and SSCM aggregate specifications (log scale)

\section{Research need}

In Sri Lanka, gradation specifications in SSCM consist of a gradation master band in which upper and lower limits of the passing percentages have been specified for most sieve sizes. Also, these limits tend to make a finer gradation according to the Superpave specified aggregate gradation (i.e. gradation falls above the Superpave maximum density line). Hence, Superpave coarser gradation is still not used in the Sri Lankan specification. Figure 2 shows the comparison of aggregate gradation of Superpave and SSCM specifications.

Avoiding the restricted zone is not mandatory in the specification, but Superpave developers have recommended avoiding it. Hence, some highway agencies unconditionally reject any mixtures passing through the restricted zone. Many state and local agencies in the US have found that asphalt mixtures, which do not meet restricted zone criteria are performing well in the field. Further, the aggregate gradations, which avoid the restricted zone may not satisfy the mix design volumetric requirements. Therefore this study is focused on the effect of Superpave specified aggregate gradation on Marshall design parameters.

\section{METHODS AND MATERIALS}

Superpave specified aggregate specification was used to develop the mixtures. The coarse side (plus $4.75 \mathrm{~mm}$ ) of the grading curve (as per SSCM) was maintained almost unchanged, while the fine side (minus $4.75 \mathrm{~mm}$ ) was varied in order to pass through, above, and below the restricted zone (Figures 3, 4 and 5). Laboratory tests were used to predict mixture characteristics. The following steps were adopted in the work plan;

\section{Material selection}

Locally available crushed granite and penetration grade bitumen $(60-70)$ were identified and collected to prepare the different mixtures. The above materials are the currently used materials for constructing wearing course in Sri Lanka. Asphalt binder and aggregate characteristics were tested and complied with the specifications (ASTM C 131, BS 812-105.1, BS 812-105.2, ASTM C 136, ASTM D 546, ASTM C 127, ASTM C 128 and ASTM C 188). Marshall mix design was carried out to determine the Marshall stability, flow, density, air voids and VMA characteristics of the mixtures.

\section{Optimum binder content determination}

The optimum binder content was determined so that it satisfies the considered Marshall criteria. The Marshall criteria and limits used in this research are shown in Table 3 (SSCM-1989 also considers these criteria and limits). Additionally, asphalt contents on the increasing (wet or right hand) side of VMA curve were avoided, even if the minimum VMA criteria were met. Design asphalt contents in this range have a tendency to bleed and/or 


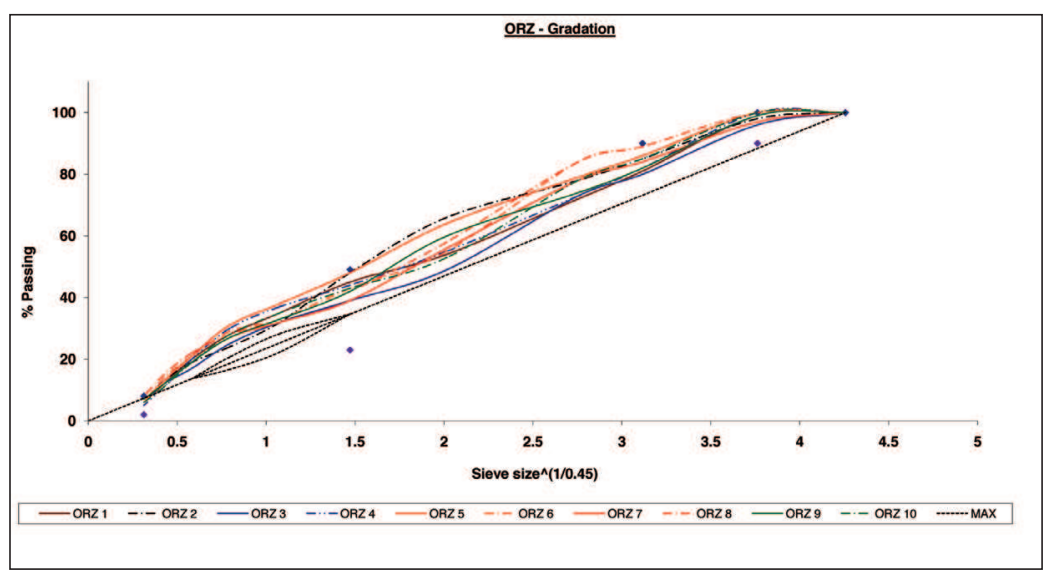

Figure 3: Gradations above the restricted zone

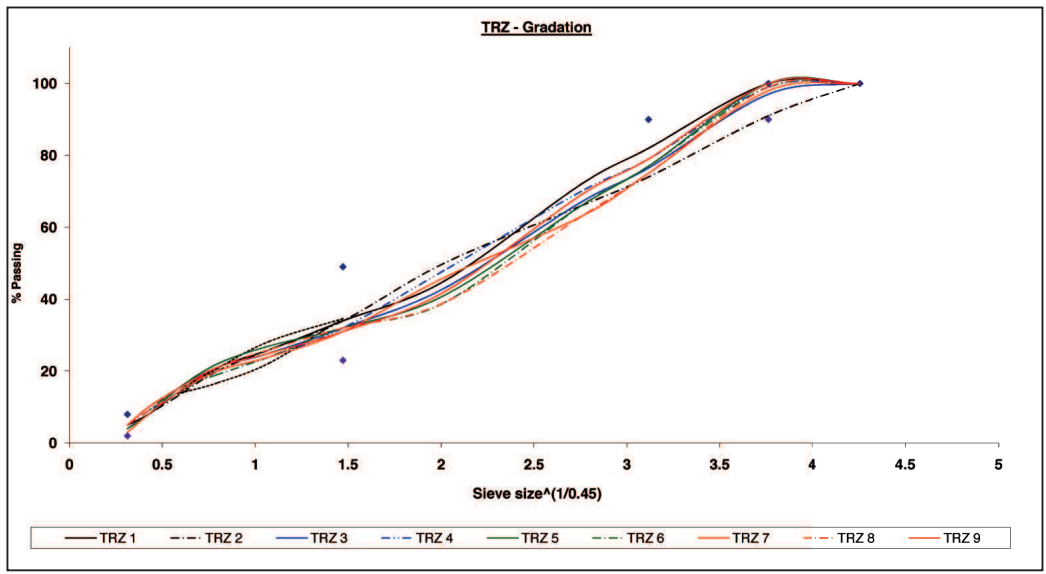

Figure 4: Gradations through the restricted zone

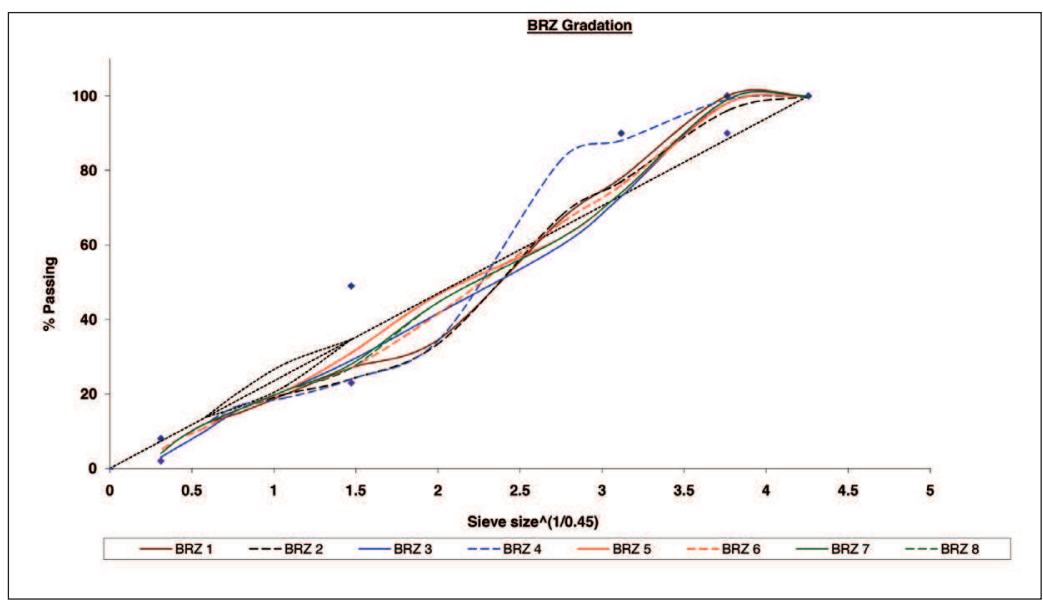

Figure 5: Gradations below the restricted zone 
Table 3: SSCM Marshall design criteria and limits

\begin{tabular}{lc}
\hline Design criteria & $\begin{array}{c}\text { Heavy traffic } \\
\left(\mathrm{msa}>10^{6}\right)\end{array}$ \\
\hline Compaction (\# blows) & 75 \\
Stability $(\mathrm{KN})$ & Min. 6.67 \\
Flow $(0.25 \mathrm{~mm})$ & $8-16$ \\
Air voids $(\%)$ & $3-5$ \\
VMA $(\%)$ & Min. 14
\end{tabular}

exhibit plastic flow when placed in the field (Asphalt Institute, 1994). Using the calculated data, graphs were drawn of asphalt content on the $\mathrm{x}$-axis versus the following on the y-axis :

- Marshall stability

- Marshall flow

- $\quad$ Percent air voids in the total mixture $(\mathrm{V})$

- $\quad$ Void in mineral aggregate (VMA)

The range of asphalt content that satisfies all the Marshall design criteria were chosen to select the optimum binder content. The design asphalt content for a particular mixture is the median value of the common range.

Marshall stability, Marshall flow, VMA and Va values were calculated at optimum binder content (OBC). Binder tolerance is a margin width of binder content that satisfies all Marshall criteria. Table 4 shows the $\mathrm{OBC}$ and the Marshal design parameters at the OBC. The allowed binder tolerances are included in the same table.
Durability of the asphalt concrete depends on the film thickness of the asphalt binder on aggregate. The surface area and the film thickness were calculated and are shown in Table 5.

\section{General observations}

For all mix designs, the pattern of Marshall parameters with bitumen content showed the following general characteristics;

a) The stability value increases with increasing bitumen content up to a maximum, after which the stability decreases.

b) The flow value consistently increases with increasing bitumen content.

c) The curve for unit weight of total mix follows the trend similar to the stability curve, except that the maximum unit weight occurs at higher bitumen content than the maximum stability.

d) The percent air voids $V_{a}$, steadily decreases with increasing bitumen content, ultimately reaching a minimum void content.

e) The percent void in the mineral aggregate, VMA, decreases to a minimum value, then increases with increasing bitumen content.

Further, it was shown that $\mathrm{V}_{\mathrm{a}}$ and VMA were the key parameters in determining the optimum bitumen content.

\section{DATA ANALYSIS AND RESULTS}

Marshall stability, flow, VMA and Va are the Marshal mix design criteria. The significance of these parameters

Table 4: Mean and standard deviation of marshall mix properties

\begin{tabular}{|c|c|c|c|c|c|c|c|c|c|}
\hline 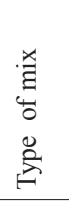 & 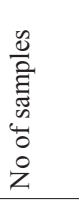 & 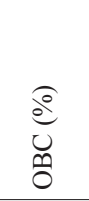 & 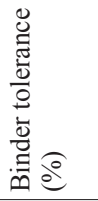 & 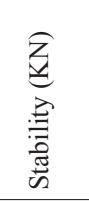 & $\sum_{j}^{\lessgtr}$ & $>^{\pi}$ & 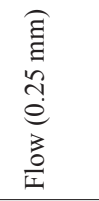 & 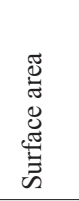 & 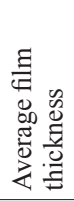 \\
\hline ORZ & 10 & $\begin{array}{c}4.70 \\
(0.23)\end{array}$ & $\begin{array}{c}0.26 \\
(0.08)^{*}\end{array}$ & $\begin{array}{l}12.42 \\
(1.98)\end{array}$ & $\begin{array}{l}14.83 \\
(0.64)\end{array}$ & $\begin{array}{c}4.16 \\
(0.27)\end{array}$ & $\begin{array}{l}12.26 \\
(1.06)\end{array}$ & $\begin{array}{l}7.161 \\
0.447\end{array}$ & $\begin{array}{l}6.463 \\
0.545\end{array}$ \\
\hline TRZ & 9 & $\begin{array}{c}4.49 \\
(0.18)\end{array}$ & $\begin{array}{c}0.19 \\
(0.10)^{*}\end{array}$ & $\begin{array}{l}13.07 \\
(1.66)\end{array}$ & $\begin{array}{l}14.47 \\
(0.35)\end{array}$ & $\begin{array}{c}4.42 \\
(0.34)\end{array}$ & $\begin{array}{l}12.22 \\
(1.79)\end{array}$ & $\begin{array}{l}5.244 \\
0.309\end{array}$ & $\begin{array}{l}8.301 \\
0.714\end{array}$ \\
\hline BRZ & $9 * *$ & $\begin{array}{c}4.22 \\
(0.12)\end{array}$ & $\begin{array}{c}0.08 \\
(0.10)^{*}\end{array}$ & $\begin{array}{l}12.83 \\
(1.88)\end{array}$ & $\begin{array}{c}14.48 \\
(0.32)\end{array}$ & $\begin{array}{c}4.77 \\
(0.27)\end{array}$ & $\begin{array}{c}10.26 \\
(1.00)\end{array}$ & $\begin{array}{l}4.434 \\
0.292\end{array}$ & $\begin{array}{l}9.222 \\
0.428\end{array}$ \\
\hline
\end{tabular}

Note: ** There were 8 mixtures which did not show an OBC with high potential of plastic deformation 
in the selected three types of mixtures was compared. The two tailed student t-test was used for the statistical analysis. A critical t-value was determined by considering the degree of freedom and a significant level of 10 percent (or confidence level of 90 percent). If the t-statistic values are within the corresponding range of the critical t-value, then the population means are not significantly different.

\section{Comparison of Marshall parameters}

\section{Marshall stability}

Table 5 presents stability comparisons of different mixture types. The comparison showed that the null hypothesis should not be rejected; this is an evidence that all types of mixtures performed equally as far as the Marshall stability is concerned. Further, TRZ and BRZ gradations (i.e. gradation below the lower boundary of aggregate gradation specified on SSCM-1989 for wearing course) did not show any significant Marshall stability difference with ORZ gradation (i.e. almost similar gradation with currently specified aggregate gradation in SSCM for wearing course).

Null hypothesis: (Population mean of stability) $)_{\mathrm{i}}=$ (Population mean of stability)

Where; $\quad \mathrm{i} \neq \mathrm{j}$

$$
\mathrm{i}, \mathrm{j}=\mathrm{ORZ}, \mathrm{TRZ}, \mathrm{BRZ} \text { (compared in pairs) }
$$

\section{Marshall flow}

The Marshall flow values of mixtures are given in Table 5.
The comparison of ORZ mixtures with TRZ indicated that the null hypothesis should not be rejected, as it revealed that the Marshall flow values of these two mixtures are not significantly different at a $90 \%$ confidence level. The null hypotheses should be rejected for the comparison of BRZ mixtures with other two mixes. The flow value of BRZ mixtures was lower than the flow value of TRZ and ORZ mixtures (since the t-statistic is greater than the positive value of critical t-value). Results show that inclusion of fine aggregates in mixtur tends to have a high flow potential.

Null hypothesis: $(\text { Population mean of flow })_{i}=($ Population mean of flow)

$$
\text { Where; } \begin{aligned}
i \neq j \\
i, j=\text { ORZ, TRZ, BRZ }
\end{aligned}
$$

\section{Void in mineral aggregate}

Comparison of VMA of mixtures is shown in Table 5. The overall comparison of VMA values indicated that the null hypothesis should be accepted in all cases. It reveals that there is no significant difference of their VMA values. Therefore, VMA values have not changed with the selected aggregate gradation. Furthermore, material passing through the restricted zone comply with the VMA requirement.

Null hypothesis: (Population mean of VMA) $)_{i}=$ (Population mean of VMA)

Where; $i \neq j$

$$
\mathrm{i}, \mathrm{j}=\mathrm{ORZ}, \mathrm{TRZ}, \mathrm{BRZ}
$$

Table 5: Comparison of Marshal mix design parameters

\begin{tabular}{llllll}
\hline Marshal properties & $\begin{array}{c}\text { Gradation } \\
\text { comparison }\end{array}$ & T-statistic & $\begin{array}{l}\text { Critical } \\
\text { T-value } \\
\text { (Y/N) }\end{array}$ & $\begin{array}{l}\text { Reject null } \\
\text { hypothesis }\end{array}$ \\
\hline \multirow{3}{*}{ Marshal stability } & ORZ & TRZ & -0.770 & 1.74 & $\mathrm{~N}$ \\
& ORZ & BRZ & -0.38 & 1.771 & $\mathrm{~N}$ \\
& TRZ & BRZ & 0.248 & 1.782 & $\mathrm{~N}$ \\
Marshal flow & ORZ & TRZ & 0.060 & 1.74 & $\mathrm{~N}$ \\
& ORZ & BRZ & 3.50 & 1.771 & $\mathrm{Y}$ \\
VMA & TRZ & BRZ & 2.236 & 1.782 & $\mathrm{Y}$ \\
& ORZ & TRZ & 1.495 & 1.74 & $\mathrm{~N}$ \\
Air voids, $V_{\text {a }}$ & ORZ & BRZ & 1.14 & 1.771 & $\mathrm{~N}$ \\
& TRZ & BRZ & -0.053 & 1.782 & $\mathrm{~N}$ \\
& ORZ & TRZ & -1.856 & 1.74 & $\mathrm{Y}$ \\
& ORZ & BRZ & -4.12 & 1.771 & $\mathrm{Y}$ \\
& TRZ & BRZ & -1.971 & 1.782 & $\mathrm{Y}$ \\
\hline
\end{tabular}




\section{Air voids $\left(V_{a}\right)$}

Table 5 shows the comparison of the $\mathrm{V}_{\mathrm{a}}$ value of different gradations. The null hypotheses are rejected for all. It further showed that $\mathrm{V}_{\mathrm{a}}$ value increased when blends become coarser (since the t-statistic is less than the negative value of critical t-value), supporting the conclusion that the coarser gradation has more voids than the finer gradation.

Null hypothesis: (Population mean of air voids) $)_{\mathrm{i}}=$ (Population mean of air voids)

Where; $i \neq j$

$$
\mathrm{i}, \mathrm{j}=\mathrm{ORZ}, \mathrm{TRZ}, \mathrm{BRZ}
$$

\section{Comparison of other parameters}

\section{Optimum binder content}

The average optimum binder contents of the three considered gradations are presented in Table 4. It shows that the binder content values vary with gradation types (i.e. ORZ, TRZ and BRZ). ORZ gradation has a relatively large binder content value, while BRZ gradation has a relatively low binder content. The comparison of average binder contents are presented in Figure 6.

\section{Binder tolerance}

The average binder tolerances of mixture types are presented in Table 4. The comparison of average binder tolerances is presented in Figure 7. It reveals that the size of the binder tolerance range varies according to the

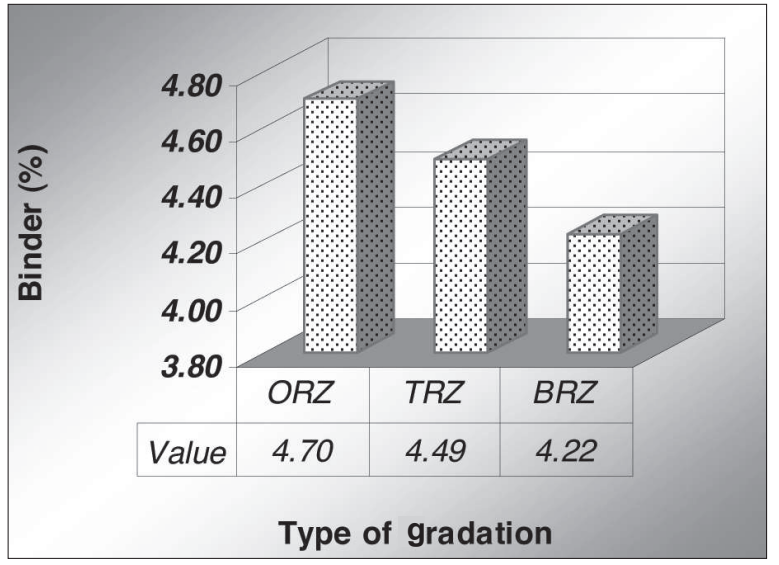

Figure 6: Optimum binder content

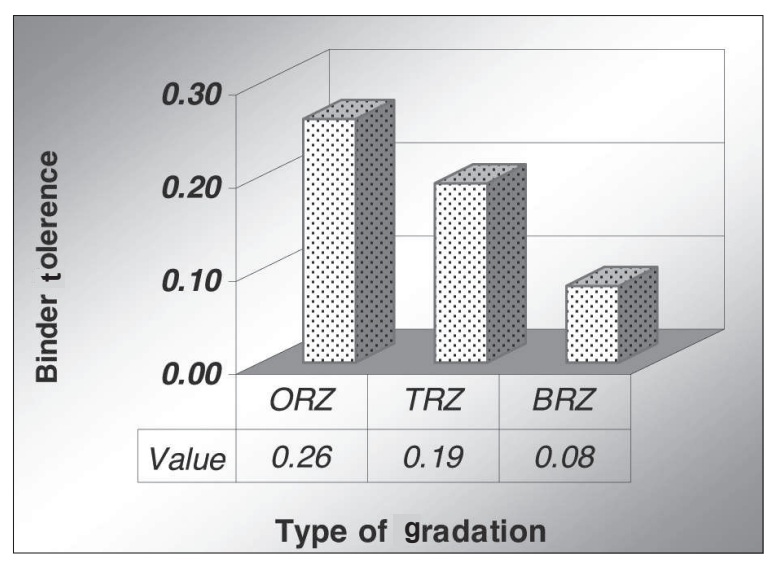

Figure 7: Binder tolerances with types of gradation

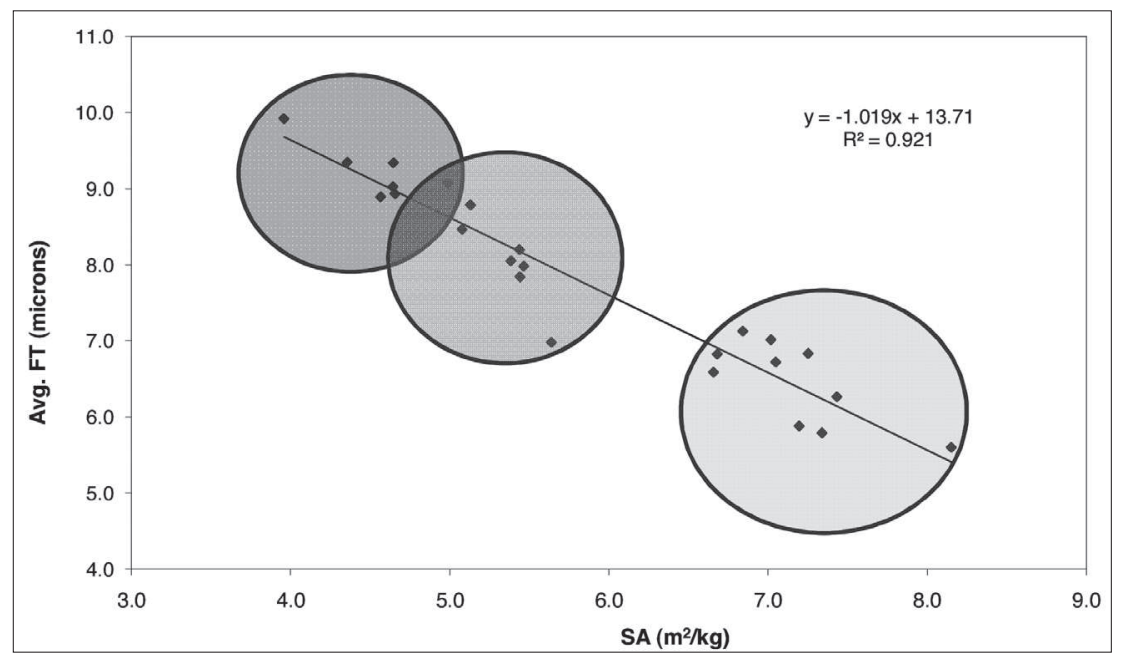

Figure 8: Surface area vs average film thickness 
considered gradation types (i.e. ORZ, TRZ and BRZ). ORZ mixtures have a large binder tolerance value (close to \pm 0.3 of the specified value in SSCM), while TRZ mixtures show slightly lower binder tolerance values than ORZ gradation. Very narrow binder tolerance value $( \pm 0.08)$ is exhibited by BRZ gradation.

The size of the adjustment range is dependent on how sensitive the mixture is to the binder content (Lavin, 2003). From this study it can be concluded that the BRZ gradation is highly sensitive to the binder content than the ORZ and TRZ gradations, while the TRZ gradation shows slightly higher sensitivity to the binder content than the ORZ gradation.

\section{Average film thickness}

The calculated surface area (SA) and average film thickness (FT) values are presented in Table 4. This comparison shows that the TRZ and BRZ mixtures have a higher binder film thickness than the ORZ mixtures. Therefore, durability of the TRZ and BRZ mixtures is high compared to the ORZ mixtures.

The correlation between surface area and average film thickness has a calculated $\mathrm{R}^{2}$ value of 0.92 , implying a reasonably high correlation between these two parameters. Furthermore, it shows a negative gradient. As found in literature, Carnpen et al. (1959) studied the relationship between surface area and film thickness and found that the film thickness decreases with increasing surface area. Figure 8 shows the relationship between film thickness and surface area for the tested samples.

\section{CONCLUSION}

Laboratory experiments were conducted to evaluate the Marshall parameters of HMA, using different aggregate gradations, which pass through, below and above the restricted zone of Superpave specified gradation. The aggregate selected for this research was 100 percent crushed granite. Stability and flow of mixtures were measured using the Marshall tester. Based on the findings, the following conclusions can be made;

1. Considered Superpave mixtures (ORZ, BRZ and TRZ) satisfied the SSCM specified Marshall criteria (Marshall stability, Marshall flow, VMA and $\mathrm{V}_{\mathrm{a}}$ ).

2. Marshall criteria were not affected by the Superpave restricted zone under local conditions and specifications.
3. Some BRZ mixtures showed a higher sensitivity to the binder content (narrow binder tolerance limits), while some mixtures showed a potential of plastic deformation.

4. The Superpave specified gradation can be used to select aggregate gradation for wearing course, with $19 \mathrm{~mm}$ nominal size crushed granite.

5. Mixtures through and below the restricted zone (coarser gradation than what is currently used) can be used for wearing courses.

6. More attention should be paid on the binder content in the production processes if the BRZ mixtures are used, since the allowed binder tolerance is low.

7. HMA with TRZ needs a low binder content and has a sufficient tolerance limit. Furthermore, it complies with the Marshall design criteria and fall within the gradation limits specified in the SSCM. Aggregate passing through restricted zone can be recommended for wearing course application in Sri Lanka subjected to field verification.

\section{REFERENCES}

1. American Society for Testing and Materials (ASTM) (2000). Annual Book of ASTM Standard, section 4: construction, volumes 4.02 and 4.03. American Society for Testing and Materials, West Conshohocken, Pennsylvania, USA.

2. Anderson R.M. \& Bahia H.U. (1997). Evaluation and selection of aggregate gradations for asphalt mixtures using superpave. Transportation Research Record No. 1583, pp. 91- 97. Transportation Research Board, National Research Council, Washington DC, USA.

3. Asphalt Institute (1994). Mix design methods for asphalt concrete and other hot-mix types. Manual Series No. 2, $6^{\text {th }}$ edition. Asphalt Institute, Lexington, Kentucky, USA.

4. Asphalt Institute (1996). Superpave mix design. Superpave Series No. 2 (SP-2). Asphalt Institute, Lexington, Kentucky, USA.

5. Atkins H.N. (1997). Highway Materials, Soils, and Concretes, $3^{\text {rd }}$ edition. Quebecor Printing, Montreal, USA.

6. Brown E.R. \& Basset C.E. (1990). The effects of maximum aggregate size on rutting potential and other properties of asphalt - aggregate mixtures. Transportation Research Record 1259. National Research Council, Washington DC, USA.

7. Brown E.R., McRae J.L. \& Crawley A.B. (1989). Effect of aggregates on performance of bituminous concrete, STP 1016. American Society for Testing and Materials, West Conshohocken, Philadelphia, USA.

8. Button J. W., Perdomo D. \& Lytton R. L. (1990). The effects of maximum aggregate size on rutting potential and other properties of asphalt - aggregate mixtures. Transportation Research Record 1259. Transportation Research Board, 
National Research Council, Washington DC, USA.

9. Carnpen W.H., Smith J.R., Erickson L.G. \& Mertz L.R. (1959). The relationships between voids, surface area, film thickness and stability in bituminous paving mixtures, Proceedings of the Association of Asphalt Pavement Technologists, volume 28, Dallas, Texas, USA, p. 149.

10. Chowdhury A., Button J.W. \& Grau J.D.C. (2001). Effect of superpave restricted zone on permanent deformation. Report No. 201-2. Texas Transportation Institute, Texas, USA.

11. Committee of State Road Authorities (CSRA) (1987). Selection and Design of Hot-Mix Asphalt Surfacings for Highways. Committee of State Road Authorities, Pretoria, South Africa.

12. Crawford C. (1989). Tender mixes: probable causes, possible remedies. Quality Improvement Series 1083186. National Asphalt Pavement Association, Lanham, Maryland, USA.

13. Elliot R.P., Ford M.C., Ghanim M. \& Tu Y.F. (1991). Effect of aggregate gradation variation on asphalt concrete mix properties. Transportation Research Board, National Research Council, Washington DC, USA.

14. Hand A. J. \& Epps A. L. (2001). Impact of gradation relative to the superpave restricted zone on HMA performance. Transportation Research Record 1767: 158 -166.

15. Hand A.J., Stiady J.L., White T.D., Noureldin A.S. \& Galal K. (2001). Gradation effects on HMA performance. Transportation Research Record 1767: 152 -157.

16. Japan Road Association (1989). Manual for Asphalt Pavement, $2^{\text {nd }}$ edition. Japan Road Association, Tokyo, Japan.

17. Jahn D.W. (1996). A closer look at superpave aggregate specification, $4^{\text {th }}$ Annual Symposium of the International Center for Aggregate Research, Atlanta, Georgia, USA, pp. $1-20$.

18. Kallas B.F. \& Griffith J.M. (1957). Influence of fine aggregate on asphalt paving mixtures. Proceedings of the Association of Asphalt Paving Technologists, volume 27, Dallas, Texas, USA.

19. Kim Y.R., Yim N. \& Khosla N.P. (1992). Effects of aggregate type and gradation on fatigue and permanent deformation of asphalt concrete, STP 1147. American
Society for Testing and Materials, West Conshohocken, Pennsylvania, USA.

20. Lavin P. (2003). Asphalt Pavements: A Practical Guide to Design, Production and Maintenanec for Engineers and Architects. Spon Press, London, UK.

21. Lottman R.R. \& Goetz W.H. (1956). Effect of crushed gravel fine aggregate on the strength of asphalt surfacing mixtures. Publication FHWA/IN/JHRP-56/12. Joint Highway Research Project, Indiana Department of Transportation and Purdue University, Indiana, USA.

22. O'Flaherty A.M. (2002). The Location, Design, Construction and Maintenance of Road Pavements, $4^{\text {th }}$ edition. Butterworth-Heinemann Publishers, Oxford, UK.

23. Road Development Authority (1989). Standard Specifications for Construction and Maintenance of Roads and Bridges. Ministry of Highways, Colombo.

24. Roberts F.L., Kandhal P.S., Brown E.R., Lee D. \& Kennedy T.W. (1996). Hot Mix Asphalt Materials, Mixture Design and Construction. National Asphalt Pavement Association, Lanham, Maryland, USA.

25. Rouque R., Huang S. C. \& Ruth B. (1997). Maximum shear resistance of asphalt mixtures by proper selection of aggregate gradation. Proceedings of the 8th International Conference on Asphalt Pavements, volume 1, University of Washington, Seattle, Washington, pp. $249-268$.

26. Shklarsky E. \& Livneh M. (1964). The use of gravels for bituminous mixtures. Proceedings of the Association of Asphalt Paving Technologists, volume 33, Dallas, Texas, USA, pp. $23-65$.

27. Tarris J. P. \& Anderson D. A. (1982). The Effects of Baghouse Fines on Mixture Design Properties, QIP 102. National Asphalt Pavement Association, Lanham, Maryland, USA.

28. Transport Research Laboratory (TRL)(2002). A guide to the design of hot mix asphalt in tropical and sub-tropical countries: Overseas Road Note 19. Transport Research Laboratory, Crowthorne House, Berkshire, UK.

29. Wright P.H. (1996). Highway Engineering, $6^{\text {th }}$ edition. Georgia Institute of Technology, Atlanta, USA.

30. Yeggoni M., Button J.W. \& Zollinger D.G. (1994). Influence of coarse aggregate size, shape, and surface texture on rutting of hot mix asphalt concrete: Report FHWA-TW94/1244-6. Federal Highway Administration and Texas Department of Transportation, Texas, USA. 